\title{
The college basketball teaching evaluation system of fuzzy evaluation
}

\author{
Chao Chen ${ }^{1,}$ a , Bing Zhang 2 , b \\ ${ }^{1}$ Institute of Physical Education, Jilin Normal University, Siping 136000, China \\ 2 Institute of Physical Education, Huanggang Normal University, Huangzhou 438000, China
}

\begin{abstract}
Using the method of documentary, questionnaire, expert interview method to study the current basketball teaching achievement evaluation system, the weakness of the system of analysis, put forward the basketball teaching evaluation system should be to address the students and teachers' attitude towards basketball general course, improve teachers' teaching and students' passion for target, so as to improve the students' basketball quality, body quality and the healthy development of basketball general course.
\end{abstract}

\section{Introduction}

Scientific and reasonable basketball public course teaching evaluation can effective propel to basketball public course education development in universities, enhance students basketball quality and physical quality, and propel to lifelong sports and other thoughts transmission among students. By far, Chinese universities basketball public course implementation just targets at test contents, evaluation recognition has deviation, evaluation contents are not comprehensive and evaluation lacks of scientificity [1-3]. For present universities basketball public course evaluation system establishment, the paper based on formers analytic investigation, applies document literature, mathematical statistics and other methods to make analytic investigation on them, and applies fuzzy evaluation method to establish corresponding evaluation model, in the hope of solving present universities basketball public course evaluation system existing problems, and provides references for universities basketball public course development and their students basketball quality improvements.

\section{Basketball public course and model analysis}

In order to analyze and study on basketball public course organization status in universities and school evaluation system about students performance, the paper selects Shandong province fifteen undergraduate universities, fifteen academies, carries on questionnaire survey on them, and implements experts consultation with partial basketball public course teachers, and makes mathematical statistics of questionnaire results and consultation. Finally, the paper carries on principal components analysis of statistical results, and establishes corresponding evaluation models on universities basketball public course [4-6].

In order to carry out effective reformation and modeling on universities basketball public course teaching evaluation system, the paper studies on present universities basketball public course teaching and teaching evaluation relative problems by experts interviewing and questionnaire survey statistics. Presently, universities basketball public course teaching contents mainly are based on most basic simple sports techniques, no elastic adjustment on teaching contents; it cannot effective let students to improve their basketball quality and physical quality, and even cannot let students to understand lifelong sports significance during learning proves. And meanwhile, in basketball learning, students recognition of basketball integrality, team attribute are not enough, students solitary and cooperation spirits are deficient, teachers also cannot effective cultivate students striving spirits of self-confidence and self-improvement, they cannot propel to their sound psychological adjustment as well as cultivate their good quality by basketball teaching. Universities basketball public course teaching should put students' subjective function and independence playing into the first place in guiding thought. But evaluation system also has many problems that lack of scientificity .In reality teaching, students tend to learn basketball for earn credits and graduation, teachers also teach as teaching requests, basketball public course hasn't yet aroused students learning and teachers teaching positivity. Teachers tend to focus on students sports learning performances while ignore students each kind of basic quality. According to documents literature, for 50 basketball teachers' questionnaires, the paper divides teachers teaching model into subject style teaching, sheep herding style teaching, traditional style teaching and actual combat style teaching four teaching models [7].

\footnotetext{
a,b Corresponding author: ${ }^{\text {a } 398704001 @ q q . c o m ; ~}$

b tiyuxi@qq.com
} 
Different teaching models correspond $\mathrm{t}$ o different evaluation system, education is root in students development, subject style teaching gives students subject function into full play, let students to get fully development in activities. In questionnaires, only 7 teachers carry out subject style teaching that occupy $14 \%$ of total number of informant teachers. Teachers with sheep herding style teaching even randomly score on students' performance rather than carrying out effective evaluation on their courses, there are 15 teachers take sheep herding style teaching that occupy $30 \%$ of total number of informant teachers. Traditional style teaching mainly is based on passing on and evaluating students most basic techniques, it is hard to let students basketball quality, physical quality and else to be realistic improved, there are 20 teachers take traditional style teaching that occupy $40 \%$ of total number of informant teachers. There are eight teachers carry out actual combat teaching that occupy $16 \%$ of total number of informant teachers. By above statistics, it is clear that present universities basketball public course teaching models are not ideal, which also causes basketball public course evaluation system to be imperfect and not standardized, its teaching model and teaching performance evaluation model need to be reformed. By above analysis, it is clear that present basketball public course teaching is not ideal, teachers' teaching models are not ideal, students satisfaction on them are poor, students interests in basketball public course and teachers teaching passions cannot be effective aroused. So establishment of universities basketball public course performance evaluation system model should take solving students and teachers attitudes on basketball public course, promoting teachers and students passions as targets, so that enhance students' basketball quality, physical quality and basketball public course healthy development [8].

According to above analysis of presently universities basketball public course teaching and teaching evaluation system existing problems, the paper reforms and models its evaluation system, applies documents literature and experts interview methods, and establishes basketball public course evaluation indicators. New established evaluation indicators should solve previous teaching evaluation problems like put more emphasis on techniques, technologies and ignores students team cooperation, team awareness, and also solve problems of students basketball quality, physical quality improvements as well as learning interests cultivation in teaching, which means the paper planned basketball public course evaluation indicators should take solving students and teachers attitudes toward basketball public course, promoting teachers and students passions as targets, so that enhance students basketball quality, physical quality and basketball public course healthy development. Above selected basketball public course test contents and indicators investigate students' basketball technology, basketball course learning status from each aspect. These statistical indicators investigate students' basketball learning mainly from sports technology, social adaptability, and psychological health. Among them, it has technical indicators targeted at students' learning technical understanding, technical applications and so on, indicators for students' social adaptability's competition awareness, competition ability and so on, and also indicators for psychological health's emotional experience, sports recognition and learning attitude, which means evaluation indicators should comprehensive, objective evaluate students basketball technology learning and basketball quality improvements.

\section{Basketball public course teaching evaluation system evaluation model establishment}

In order to analyze whether above established universities basketball public course evaluation system is fit for universities students' basketball public course evaluation or not, the paper carries on fuzzy evaluation on selected indicators. According to above analysis as well as basketball public course teaching evaluation indicators establishment, it is clear that basketball public course teaching evaluation indicators has hierarchies, with respect to this, the paper adopts multiple layer fuzzy comprehensive evaluation method to make analytic studies on the problem. Finally, by establishing basketball public course teaching evaluation model, the paper provides references for universities basketball public course development and their students basketball quality improvements.

\subsection{Fuzzy evaluation system brief introduction}

Fuzzy comprehensive evaluation method is a kind of systematical analysis method that is fuzzy deduction-oriented, applies fuzzy mathematical principles to make comprehensive evaluation on things that suffer multiple factors impact and are difficult to be effectively quantitative analyzed. The paper selected basketball public course evaluation indicators wholly belong to qualitative indicators, the paper applies fuzzy comprehensive evaluation method, carries out quantitative analysis of selected qualitative indicators. By analyzing problems, set evaluation elements system indicators factors domain of discourse for comprehensive evaluation objects factors, evaluation elements set is:

$U=\left\{u_{1}, u_{2}, \cdots, u_{n}\right\}$

Among them, $u_{1}$ is the first layer evaluation element in evaluation domain of discourse. For relative complex evaluation coefficient, its evaluation elements may be in multiple layers, the paper is two layer evaluation system, set the second layer evaluation element set is: $u_{1}=\left\{u_{11}, u_{12}, \cdots, u_{1 m}\right\}, u_{2}=\left\{u_{21}, u_{22}, \cdots, u_{2 m}\right\}$, ., $u_{1}=\left\{u_{n 1}, u_{n 2}, \cdots, u_{n m}\right\}$

Remark set definition. Fuzzy comprehensive evaluation needs to transform fuzzy, qualitative indicator information into quantitative indicator information, so that carry out fuzzy comprehensive evaluation analysis on them. Here, it needs to define remark grade domain of discourse $V$, from which: $V=\left\{v_{1}, v_{2}, \cdots, v_{n}\right\}$ 
General used remarks are $\mathrm{V}=\{$ Very good, good, general, ..., not good, bad, very bad $\}$.

3)Carry out single factor evaluation. Carry out single factor weight defining on defined indicators layers, it needs to establish fuzzy relation matrix R:

$$
R=\left[\begin{array}{cccc}
r_{11} & r_{12} & \cdots & r_{1 n} \\
r_{21} & r_{22} & \cdots & r_{2 n} \\
\vdots & \vdots & \ddots & \vdots \\
r_{m 1} & r_{m 2} & \cdots & r_{m n}
\end{array}\right]
$$

Among them, $r_{i j}$ is each evaluation element $U_{\mathrm{i}}$ membership relation with $\mathrm{V}_{\mathrm{j}}$ in remark grade domain of discourse $V$, and $0 \leq r_{i j} \leq 1$.

4)Define each evaluation element membership relations with evaluated things that is to allocate weight on each element. Set evaluation factor weight vector $A=\left\{\mathrm{a}_{1}\right.$, $\left.\mathrm{a}_{2}, \ldots, \mathrm{a}_{\mathrm{m}}\right\}$, from which $A$ each element membership relations with evaluated things. Define evaluation factors weight vector $A$ weight a $\mathrm{k}_{\mathrm{k}}$ methods are mainly frequency statistical method, fuzzy analytic hierarchy process and so on.

5)Select proper fuzzy calculation operators, do fuzzy computation on evaluation factor weight vector $A$ and fuzzy relation matrix $R$, finally proceed with form handling with fuzzy comprehensive evaluation results, and get required forms.

\subsection{Fuzzy evaluation system establishment}

\subsubsection{Fuzzy evaluation system weight defining}

Basketball public course evaluation indicators have hierarchies, the paper adopts fuzzy analytic hierarchy process method, applies experts knowledge, information to solve each element distribution weight problems. When analytic hierarchy process defines each factor weight, it adopts paired comparison method, establish comparison judgment matrix, so as to convert experts information into mathematical problems. In comparison judgment matrix, each element value defining can refer to Table 1.

Table 1. Saaty(1-9 Ratio scale table).

\begin{tabular}{|c|c|}
\hline $\begin{array}{l}\text { Scale } \\
\text { scores }\end{array}$ & Definition \\
\hline 1 & $\begin{array}{l}\text { Indicates two factors have equal importance } \\
\text { by comparing }\end{array}$ \\
\hline 3 & $\begin{array}{c}\text { Indicates the former is slightly more } \\
\text { important than the later by comparing two } \\
\text { factors }\end{array}$ \\
\hline 5 & $\begin{array}{l}\text { Indicates the former is obviously more } \\
\text { important than the later by comparing two } \\
\text { factors }\end{array}$ \\
\hline 7 & $\begin{array}{l}\text { Indicates the former is intensely more } \\
\text { important than the later by comparing two } \\
\text { factors }\end{array}$ \\
\hline 9 & $\begin{array}{l}\text { Indicates the former is extremely more } \\
\text { important than the later by comparing two } \\
\text { factors }\end{array}$ \\
\hline $2,4,6,8$ & $\begin{array}{l}\text { Indicates middle value of corresponding } \\
\text { judgment that former factor to later factor }\end{array}$ \\
\hline
\end{tabular}

\begin{tabular}{cc}
\hline Reciproc & It indicates the later factor importance to \\
al of & former factor by comparing two factors \\
above & \\
numerical & \\
values & \\
\hline
\end{tabular}

By paired comparison method, establish first layer basketball public course evaluation indicator paired comparison matrix, and do consistency test on it. The first layer basketball public course evaluation indicators are sports technology, sports awareness, physical health, social adaptability and psychological health five indicators, established paired comparison matrix each element value is as Table 2 shows.

Carry out feature value and feature vector solution on Table 6 data composed matrix, it gets maximum feature value as 5.4089, and its corresponding feature vector is:

$$
w=\left[\begin{array}{lllll}
-0.1260 & -0.7847 & -0.0812 & -0.5056 & -0.3258
\end{array}\right]^{T}
$$

Judgment matrix is five orders matrix that $n=5$, and then its corresponding $R I$ value is 1.12 , and meanwhile by above, it is clear that matrix feature vector, $\lambda=5.4089$. Finally, by consistency indicators formula $\mathrm{CR}=\frac{C I}{R I}$ and $\mathrm{CI}=\frac{\lambda-n}{n-1}$, it can solve consistency indicator is 0.0912 that consistency indicator is less than 0.10 , judgment matrix consistency can be accepted. Make normalization handling with feature vector $\mathrm{w}$, it solves basketball public course evaluation indicator system first grade indicator weight is : $A=\left(\begin{array}{lllll}0.0691 & 0.4304 & 0.0445 & 0.2773 & 0.1787\end{array}\right)$

Similarly, apply above stated methods, it defines basketball public course second layer evaluation indicators weights, totally corresponding establish five paired comparison matrix, it can solve weight as following shows:

$$
\begin{aligned}
& A_{1}=\left(\begin{array}{lllll}
0.1736 & 0.3272 & 0.0899 & 0.3615 & 0.0476
\end{array}\right), \\
& A_{2}=\left(\begin{array}{llll}
0.5083 & 0.2653 & 0.0752 & 0.1512
\end{array}\right) \\
& A_{3}=\left(\begin{array}{lll}
0.2583 & 0.1047 & 0.6370
\end{array}\right), \\
& A_{4}=\left(\begin{array}{lllll}
0.2448 & 0.4896 & 0.0848 & 0.1336 & 0.0472
\end{array}\right) \\
& A_{5}=\left(\begin{array}{lll}
0.3333 & 0.3333 & 0.3333
\end{array}\right)
\end{aligned}
$$

Table 2. Basketball public course first layer indicators each factor comparison judgment matrix.

\begin{tabular}{cccccc}
\hline & $\begin{array}{c}\text { Sports } \\
\text { techno } \\
\text { logy }\end{array}$ & $\begin{array}{c}\text { Sports } \\
\text { aware } \\
\text { ness }\end{array}$ & $\begin{array}{c}\text { Physic } \\
\text { al } \\
\text { health }\end{array}$ & $\begin{array}{c}\text { Social } \\
\text { adapta } \\
\text { bility }\end{array}$ & $\begin{array}{c}\text { Psych } \\
\text { ologic } \\
\text { al } \\
\text { health }\end{array}$ \\
\hline $\begin{array}{c}\text { Sports } \\
\text { techno } \\
\text { logy }\end{array}$ & 1 & $1 / 5$ & 3 & $1 / 5$ & $1 / 5$ \\
$\begin{array}{c}\text { Sports } \\
\text { aware } \\
\text { ness }\end{array}$ & 5 & 1 & 5 & 3 & 3 \\
$\begin{array}{c}\text { Physic } \\
\text { al }\end{array}$ & $1 / 3$ & $1 / 5$ & 1 & $1 / 5$ & $1 / 5$ \\
health & & & & & \\
$\begin{array}{c}\text { Social } \\
\text { adapta } \\
\text { bility }\end{array}$ & 5 & $1 / 3$ & 5 & 1 & 3 \\
\hline
\end{tabular}




\begin{tabular}{cccccc}
\hline $\begin{array}{l}\text { Psych } \\
\text { ologic } \\
\text { al } \\
\text { health }\end{array}$ & 5 & $1 / 3$ & 5 & $1 / 3$ & 1 \\
\hline
\end{tabular}

\subsubsection{Fuzzy evaluation system membership matrix defining}

By above analysis, it is clear that the paper first layer evaluation element domain of discourse $U$ each element is above selected sports technology, sports awareness, physical health, social adaptability and psychological health five indicators, in the second layer evaluation element domain of discourse is first layer five indicators respective corresponding sub indicators. The paper takes one student performance evaluation as an example, and meanwhile, the paper set remark grade as five grades that domain of discourse $\mathrm{V}=\{$ Very good, good, general, not good, very bad\}

Based on above domain of discourse, define basketball public course performance evaluation model fuzzy membership matrix. There are more methods to define fuzzy membership matrix, the paper applies frequency statistical methods. In designed system, in teachers teaching process, evaluate ten times on each kind of indicators, membership of indicators to domain of discourse each element is the ratio between selecting element times and total times 10 , so that it can get students term end basketball performance information, and can also fully evaluate on students performance change information in learning.In order to define exact scores on students' performance, it can calculate five grades memberships. The paper multiplies very good, good and general three grades membership sum by 100 , its obtained result is used for established fuzzy evaluation coefficient scores.

\subsubsection{Fuzzy evaluation system application}

Carry out membership vector calculation on basketball public course second grade evaluation indicators, its computational formula is: $\mathrm{Bi}=\mathrm{Ai} \times \mathrm{Ri}$

Among them, $i=1,2,3,4,5$. It can solve second grade evaluation indicator membership vectors as following:

$$
\begin{aligned}
& B_{1}=\left(\begin{array}{lllll}
0.1329 & 0.2959 & 0.4846 & 0.0816 & 0.0048
\end{array}\right) \\
& B_{2}=\left(\begin{array}{lllll}
0.0682 & 0.4303 & 0.3698 & 0.0734 & 0.0075
\end{array}\right) \\
& B_{3}=\left(\begin{array}{lllll}
0 & 0.0258 & 0.2000 & 0.5428 & 0.2314
\end{array}\right) \\
& B_{4}=\left(\begin{array}{lllll}
0.0734 & 0.2359 & 0.3802 & 0.2350 & 0.0754
\end{array}\right) \\
& B_{5}=\left(\begin{array}{lllll}
0.1666 & 0.3000 & 0.3000 & 0.1333 & 0.1000
\end{array}\right)
\end{aligned}
$$

Similarly, by formula $B=A \times R$, it can also solve first grade evaluation indicators membership vectors, from which $\mathrm{R}$ is fuzzy membership vectors transposed matrix that is composed of line vector $\mathrm{Bi}$. Then it can solve first grade evaluation indicators membership vector after normalization

is: $B=\left(\begin{array}{lllll}0.1816 & 0.2281 & 0.2119 & 0.2022 & 0.2088\end{array}\right)$

\subsection{Fuzzy evaluation result analysis}

By above, it is clear that the paper divides students evaluation into five grades that fuzzy evaluation domain of discourse elements are very good, good, general, not good, very bad. By above computed result, it is clear that the paper selected student performance to five grades memberships are respectively $0.1816 、 0.2281,0.2119$ 、 0.2022 and 0.2088 . That student performance membership to very good, good and general three grades is 0.6216 , and membership to not good and very good two grades is 0.3784. By the paper established evaluation system, evaluated student performance is 62.12 points.

\section{Conclusions}

The paper applies fuzzy mathematical knowledge, establishes universities basketball evaluation system. Established evaluation system comprehensive investigates students' basketball technology and learning attitudes from each aspect, it can comprehensive evaluate on students basketball public course learning. Due to selected basketball indicators relations are relative complex and fuzzy. When evaluate each student performance, defining of its each indicator corresponding numerical value is relative fuzzy, and selected indicators have hierarchies, so it chooses fuzzy comprehensive evaluation method, it can effective apply teachers experiences and others. Basketball public course fuzzy comprehensive evaluation system establishment will effective solve current universities basketball public course performance evaluation system existing problems, and provides references for universities basketball development.

\section{References}

1. B.M. Su, Z.X. Liu, C.M. Liu, Journal of Jinan University, 12, 5 (2002).

2. N.Y. Chen, Journal of Yunnan Finance and Trade Institute, 21 (2005).

3. C.M. Liu, B. Guan, Journal of Tianjin University(Social Sciences), 11 (2009).

4. L.W. Fan, J.Y. Liang, Value Engineering, 25 (2006).

5. X.G. Wang, Research On Development, 5 (2007).

6. J.H. Lu, Journal of Anhui University(Philosophy \& Social Sciences) 30 (2006).

7. X.Y. Xu, Journal of Anhui University(Philosophy \& Social Sciences) 30 (2006).

8. H. Huang, Z.L. Liu, International Conference On Engineering And Business Management, 1-8 (2010).

9. Z. Zhao, J. Zhao, P. Xin, Journal of Coastal Research, 32

(2016). 